\title{
Effectiveness of GeoGebra towards Students' Active Learning, Performance and Interest to Learn Mathematics
}

\author{
Etienne Nzaramyimana $^{1}$, Emeritha Mukandayambaje ${ }^{2}$, Leopold Iyamuremye ${ }^{3}$, Venuste Hakizumuremyi ${ }^{4}$, \\ Fidele Ukobizaba ${ }^{5}$ \\ 1,2,3,4,5 African Centre of Excellence for Innovative Teaching and Learning Mathematics and Science (ACEITLMS), University of \\ Rwanda - College of Education (UR-CE), Kayonza, PO Box 55 Rwamagana, Rwanda \\ ${ }^{1}$ ORCID: https://orcid.org/0000-0001-5119-3533 \\ ${ }^{5}$ ORCID: https://orcid.org/0000-0003-1502-2395
}

\begin{tabular}{ll}
\hline ARTICLE INFO & ABSTRACT \\
\hline Published Online: & The present study explored the effectiveness of GeoGebra in enhancing students' active learning, \\
& performance and interest to learn mathematics. Much emphasis was put in teaching and learning \\
& exponential and logarithmic functions. The general intention was to investigate whether the use of \\
& ICT be used to improve the teaching and learning of mathematics in Rwandan Secondary Schools. \\
& The present study is an experimental research design that employed Grade 11 students of one \\
& secondary school within Kayonza district of Rwanda. Thus, sample of 34 Grade 11 students were \\
& taught exponential and logarithmic functions with the use of GeoGebra from 19 August 2019 to 30 \\
& October 2019. Before the intervention, a short group discussion with Grade 11 students was conducted \\
& to see the students' attitudes about learning mathematics using ICT tools. Besides, a mathematics \\
& teacher was asked a challenging topic to teach within conventional classroom. After learning with the \\
& use of GeoGebra, an attitudinal survey questionnaire was used to collect quantitative data about the \\
& effectiveness of GeoGebra in learning mathematics. Data were analyzed descriptively using Excel \\
& 2016. It was found that students acquired more knowledge. The study showed that students can learn \\
& independently through interactive dynamic software. The results, therefore, showed that students' \\
interest to learn mathematics increased. There is a need to strengthen one laptop per student program \\
to enhance students' independent learning of mathematics.
\end{tabular}

Nzaramyimana

KEYWORDS: Active Learning, Exponential And Logarithmic Functions, GeoGebra, Mathematics, Students' Interest, Teaching And Learning.

\section{INTRODUCTION}

In this modern era where technology is becoming a custom of the current generation, integrating the medium that can satisfy learners' interest is notable (Moore, 2008; Saha, Ayub, \& Tarmizi, 2010; Akkaya, Tatar, \& Kağizmanli, 2011; Shadaan \& Eu, 2013; Wassie \& Zergaw, 2019). The educational system in the $21^{\text {st }}$ century focuses on globalization and internalization. Following this line, Information and Communication Technology (ICT) is required to give a significant contribution to education. This requires educators to have the prerequisite of ICT resources including software, hardware, and the curricula which are designed to support collaborative and learner-centered approaches (REB, 2015;
Brown, 2017). Technology provides access to phenomena that were previously abstract for many students (Lombardi, 2007). It is the reason why Rwanda, in line of Vision 2030, has an ambition of becoming a knowledge-based and technology-led economy by emphasizing on the need of generating, disseminating, and acquiring scientific skills and technological innovations. This requires Rwanda to adopt a policy of integrating technology in social and economic development by applying ICT in education especially in the field of applied and natural sciences in line with the implementation of a Competence-Based Curriculum (REB, 2015). Though ICT does not automatically enhance the learning of students or replace a teacher (Boholano, 2013), 
however, technology is a good tool for education of $21^{\text {st }}$ century and online activities that can replace to some extent face-to-face interactions (McCoog, 2008). One of these tools is GeoGebra.

There are many software packages used in mathematics education which are costly but GeoGebra is available free and open access on the web in 45 languages and it can be used both online and offline. GeoGebra is judged effective since its integration enhanced lesson delivery and stimulated students towards their learning and thus, enhanced students' academic achievements (Wassie \& Zergaw, 2019). GeoGebra is dynamic multi-platform mathematical software developed by Markus Hohenwarter in 2002 to facilitate the learning of mathematics. GeoGebra enables the production of selfstanding dynamic worksheets as interactive java applets rooted in hypertext markup language (HTML) pages equipped with vibrant constructions and interactive calculations (Velichová, 2011). GeoGebra is a good tool for teaching and learning geometry, algebra, and calculus. GeoGebra helps students to do mathematics in experimental ways (Hohenwarter \& Fuchs, 2004). For example, with GeoGebra students can estimate the perimeter of the circle by drawing the circle with the mouse and students can also manipulate the equation of the circle and see how it changes in graphic view (Hohenwarter \& Fuchs, 2004). In addition, Hohenwarter and Fuchs (2004), Saha, Ayub, and Tarmizi (2010) and Vasquez (2015) pointed out that GeoGebra can be used for demonstration, visualization, construction/ drawing tools in Geometry, and discovery of mathematics where students can create their own knowledge. Hohenwarter and Preiner (2000) noted that GeoGebra is software that can be used in teaching and learning mathematics from middle schools to university level. GeoGebra helps students to study mathematics not only in the classroom but also at home (Dikovi, 2009; Charles and Gladys, 2018). Therefore, GeoGebra and other dynamic mathematics software packages integration in teaching and learning mathematics may increase students' achievements both in the internal and external examination, at the same time enhancing positive attitudes towards mathematics (Akanmu, 2016).

Therefore, there is a need to shift from a routine and rote learning dominated by abstract mathematical concepts with incorporating technology into mathematics classroom, where visualization is a valuable competence and a key of mathematical thinking (Saha et al., 2010; Dockendorff \& Solar, 2018). Teachers should therefore embrace the new coming and evolving technology and endeavor to implement it in the classroom to make their students love mathematics and therefore get actively involved in constructing their knowledge. The general intention was to investigate whether the use of ICT can be used to improve the teaching and learning of mathematics in Rwandan Secondary Schools. The current study sought to explore Grade 11 students' interaction with GeoGebra software while exploring the relationships between logarithmic and exponential functions, in one of the secondary schools within Kayonza District, Rwanda. Thus, the presented study was specifically guided by the following research questions:

1) What are students' attitudes about interacting with ICT tools while learning mathematics?

2) What is the added value brought about by the use of GeoGebra in teaching and learning mathematics?

\section{LITERATURE REVIEW}

\section{Technological need in teaching and learning mathematics}

Since the early 1980s, a range of software has been developed for the purpose of helping teachers and students use computers as teaching and learning tools through exploration rather than just as drill machines (Clements \& Battista, 1992). The main purpose of these technological developments was to guide students through a discovery process that encourages students to first visualize and analyze a problem and then make conjectures before attempting a calculation or a proof. Different educational researchers (e.g. Niess, 2002; Biyela, 2008; Botha, 2011) have studied how mathematics can be taught to enhance students' motivation and achievement. In addition, technology helped the students to understand mathematical concepts and influences how effectively mathematics is taught (Philip, Wozney, \& Venkatesh, 2006; Ertmer \& Ottenbreit-Leftwich, 2010). Waxman, Connell, and Gray (2002) revealed that students who use technology in their learning improve their learning outcomes better than those who learned without technology. In particular, the use of dynamic software like GeoGebra in teaching and learning creates an interactive learning environment and allows students to explore, collaborate with their peers and create their own knowledge (Vasquez, 2015). For example, Mustafa (2015) in his study while teaching limit and continuity of a function at the secondary level, found that the students in the experimental group advanced in their conceptual understanding of limits and continuity after the intervention of GeoGebra better than the control group. Furthermore, Funkhouser (2003) found that teaching and learning Geometry computer augmented activities improves students' understanding of the geometrical concepts than students who have underwent traditional approaches. The use of technology is therefore vital since it serves as a methodology of intervention in education, and offers the learning content and objectives as a medium to develop the teaching and learning process (Voogt, 2008).

\section{Effectiveness of GeoGebra in enhancing students' interest in learning mathematics}

There are various studies that have been carried out and found that the use of GeoGebra in the teaching and learning of mathematics enhances students' interest (Arbain \& Shukor, 2015; Singh, 2018; Wassie \& Zergaw, 2019; Jusufi \& Kitanov, 2019). For instance, Arbain and Shukor (2015) carried a study on teaching and learning mathematics with 
special reference to statistics. Using GeoGebra as an intervention, the study revealed that GeoGebra can enhance student's perception in terms of motivation and confidence in learning mathematics, statistics for example. Similarly, with visual learning tools equipped by GeoGebra, this geometric dynamic mathematical software was found to enhance secondary school students' achievement and motivation in the learning coordinate geometry (Saha, Ayub, \& Tarmizi, 2010; Vasquez, 2015). In addition to these skills, visuals help grab students' attention and engage them in their learning (Shabiralyani et al., 2015). Likewise, GeoGebra and other dynamic mathematics software can enhance the ability of students in visualizing the mathematical elements which make them interact with mathematical concepts either individually or in groups (Saha et al., 2010).

Kemp (2006) conducted a study on students' self-engagement and found that students were happy and actively engaged in the lesson using GeoGebra software whereby students explored and went beyond what was assigned by the teacher. Besides, it was observed that GeoGebra software has a positive outcome in motivating students toward learning and retaining their knowledge for a longer time (Choi, 2010; Khobo, 2015). Furthermore, GeoGebra helps the students to learn independently or in collaboration with others either in the classroom or outside (Gladys, 2018). Shadaan and Eu, (2013) argued that GeoGebra is an effective tool that enhances teaching and learning Geometry and calculus. The results of this study are in accordance with Saha et al.' s (2010), Zengin, Furkan, and Kutluca' s (2012) and Shadaan and Eu' s' (2013) findings which showed the positive effects of using GeoGebra as a result motivating the students towards learning of geometry. According to Bester and Brand (2013), students become motivated and improve their thinking skills when given the opportunities to explore the available technological resources. Although, literature is full of benefits in students' achievements when using technology in general and GeoGebra in particular, however, the present study brings its contribution in capturing secondary school students' attitudes while interacting with GeoGebra in mathematics lessons whereby technology tools are not yet fully embedded in the teaching and learning process.

\section{RESEARCH METHODOLOGY}

The present study is an experimental study. With an experimental study, researchers introduce an intervention and then study the effects (Cohen, Manion, \& Morrison, 2007, p. 253). This study was conducted in one of the secondary schools within Kayonza District, from 19 August, 2019 to 30 October, 2019. The sample constitutes 34 Grade 11 students. Grade 11 students were selected because they are able to respond freely in evaluating and judging accurately how they are taught while answering a survey questionnaire. In addition, Grade 11 students sometimes use computers within their School while learning other subjects. Thus, before the intervention of teaching logarithmic and exponential function using GeoGebra, students were given a semi-structured interview about comparing learning mathematics within conventional classroom with when learning using ICT tools. To conduct our study, the six milestones with their corresponding guiding questions for each milestone were developed and implemented. The research methodology process is summarized in table 1 .

Table 1. Milestones and corresponding guiding questions of the research process

\begin{tabular}{|c|c|c|}
\hline Milestone number & Activity & Guiding question \\
\hline One & The conception of the study & $\begin{array}{l}\text { How can the use of ICT be used to improve the teaching and } \\
\text { learning of mathematics in Rwandan Secondary Schools? }\end{array}$ \\
\hline Two & Plan and timeline & Who does what and when? \\
\hline Three & Fieldwork & $\begin{array}{l}\text { Which mathematics subject areas are the most challenging for } \\
\text { teachers to handle and effectively teach and why? } \\
\text { What are the students' attitudes towards learning mathematics by } \\
\text { using ICT tools? }\end{array}$ \\
\hline Four & Selection of the subject area & $\begin{array}{l}\text { Which mathematics subject area can effectively be taught using } \\
\text { which ICT resources? }\end{array}$ \\
\hline Five & Plan for action & Are we (researchers) prepared to effectively take action? \\
\hline Six & $\begin{array}{l}\text { Taking action: Data analysis } \\
\text { and interpretation }\end{array}$ & $\begin{array}{l}\text { How did the use of GeoGebra add value to the teaching and } \\
\text { learning of exponential and logarithmic functions? }\end{array}$ \\
\hline
\end{tabular}

In milestone one, researchers conceived the study by asking themselves how ICT can be used to improve the teaching and learning of mathematics in Rwandan Secondary Schools. In milestone two, researchers developed an action plan. In milestone three, researchers went to Secondary School X (for confidential reasons) prior to getting permission from head teachers, and students were observed while learning in their conventional classroom settings. The school $\mathrm{X}$ was selected because it has computer labs where students sometimes learn mathematics using ICT tools. After observation, the mathematics teacher was asked to give the most challenging topics to teach with conventional methods. The teacher 
identified Exponential and Logarithmic function and Space Geometry: "Points, Straight lines, Planes and Sphere in 3D". In milestone four, researchers selected randomly Exponential and Logarithmic functions and were taught with the use of ICT tool commonly known as GeoGebra software. In milestone five, researchers prepared the required pedagogical documents, such as lesson plans, content books, and the syllabus of mathematics.

Researchers installed GeoGebra software in their computers (laptops), explored the installed software, and then microteaching was done prior to having a real classroom teaching. In milestone six, researchers went to the school, 34 students were taken to the computer laboratory and each student learnt using a computer. During instructions, one researcher gave instructions on how to graph the given functions and helped students and thereafter helped students to find out the relationship between exponential and logarithmic functions using GeoGebra.

The leading researcher gave instructions for each step, and students followed instructions. Besides, the other four researchers were moving into students responding to the needs of students and helped them. Each researcher was assisting eight to nine students. However, the faster students could assist their fellow slow learners within the activity. Within this study, researchers were mostly interested to see how students interact actively with the computer using GeoGebra software to explore the relationship between exponential and logarithmic functions. To track students' views and the level of satisfaction with the use of GeoGebra, students were given an attitudinal survey questionnaire.
The data collection tool was survey questionnaire. Data collected from the survey questionnaire was analyzed descriptively using Excel 2016.

\section{RESULTS PRESENTATION AND DISCUSSION}

While conducting a short group discussion with Grade 11 students, students have reported that they sometimes use ICT tools while learning different subjects. Students argued that the use GeoGebra and other soft wares can enhance their understanding of difficult concepts in mathematics. Students agreed that they enjoy interacting with ICT tools. Students also reported that, with the use of GeoGebra, they can be able to visualize with accuracy and interpret different graphs. Students further confirmed that with the use of ICT tools will make them understand more the mathematics subject.

While exploring the effectiveness of GeoGebra while learning mathematics, a lesson was delivered with GeoGebra assisted mathematics instruction, where students interacted with the software with the help of the researchers. The lesson began with a brief introduction on how to use GeoGebra. During lesson delivery, the following mathematical activities were given to students:

1) Sketch using GeoGebra the following functions on the same set of axes

$$
\begin{aligned}
& y=2^{x} \quad ; y=8^{x} \quad ; \quad y= \\
& \left(\frac{1}{2}\right)^{x}
\end{aligned}
$$

2) Using GeoGebra, enter $y=a^{x}$ into the input bar and use the feature of a slider to change the value of a

The students' activities results are illustrated below.

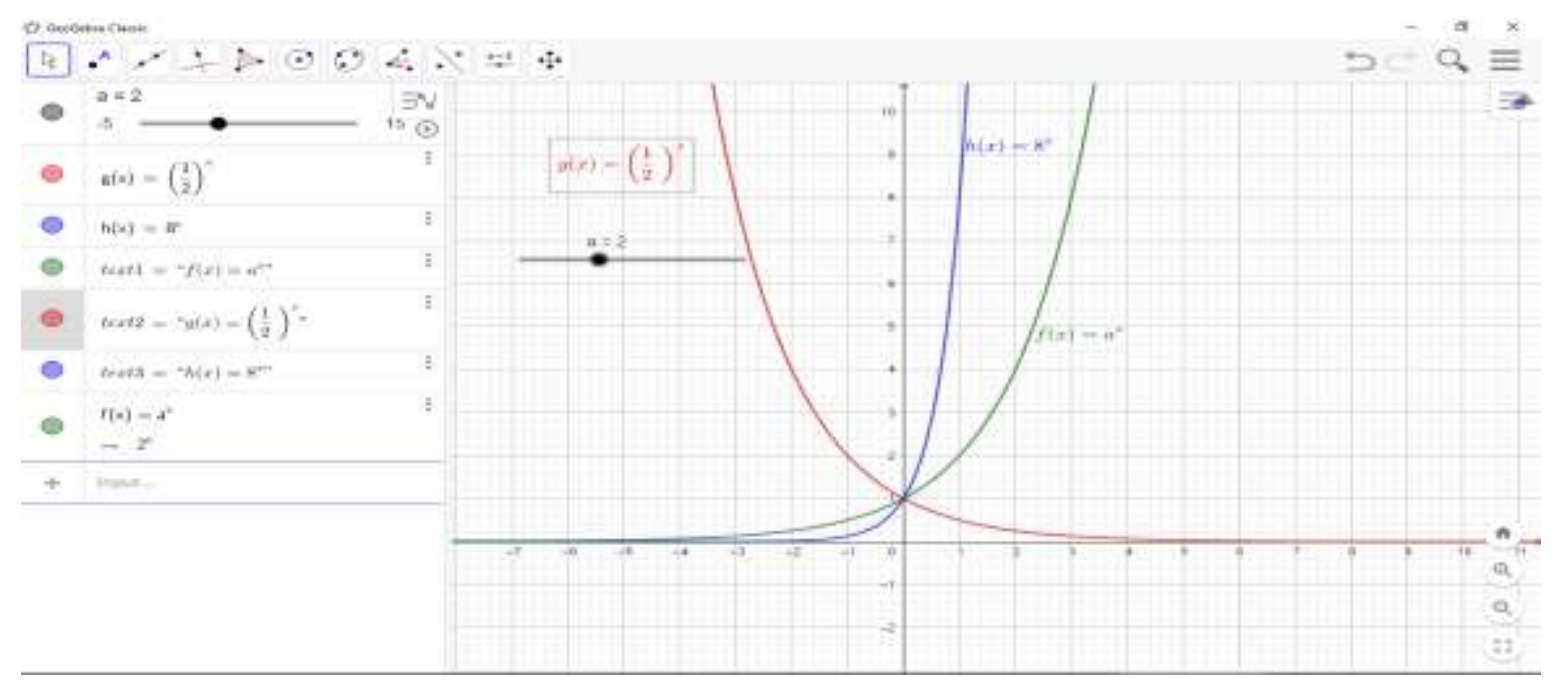

Fig.1 Students performing given activities

The students observed the effects of varying the value of $a$ and found the important properties of these graphs of the form $f(x)=a^{x}$ (where $a>0$ ). They found that when $a=1$, they get constant function $f(x)=1$; when $a>1$, the function increases rapidly for positive $x ; 0<a<1$, the function is decreasing and they found that for any value of $a$, the graph always passes through the point $(0,1)$. The graph of $f(x)=$ $\frac{1}{a^{x}}$ is a reflection, in the vertical axis, of the graph of $f(x)=$ $a^{x}$

3) Using GeoGebra, enter $y=\log _{a} x$ into the input bar and use the feature of a slider to change the value of a 
The students' activities results are illustrated below.

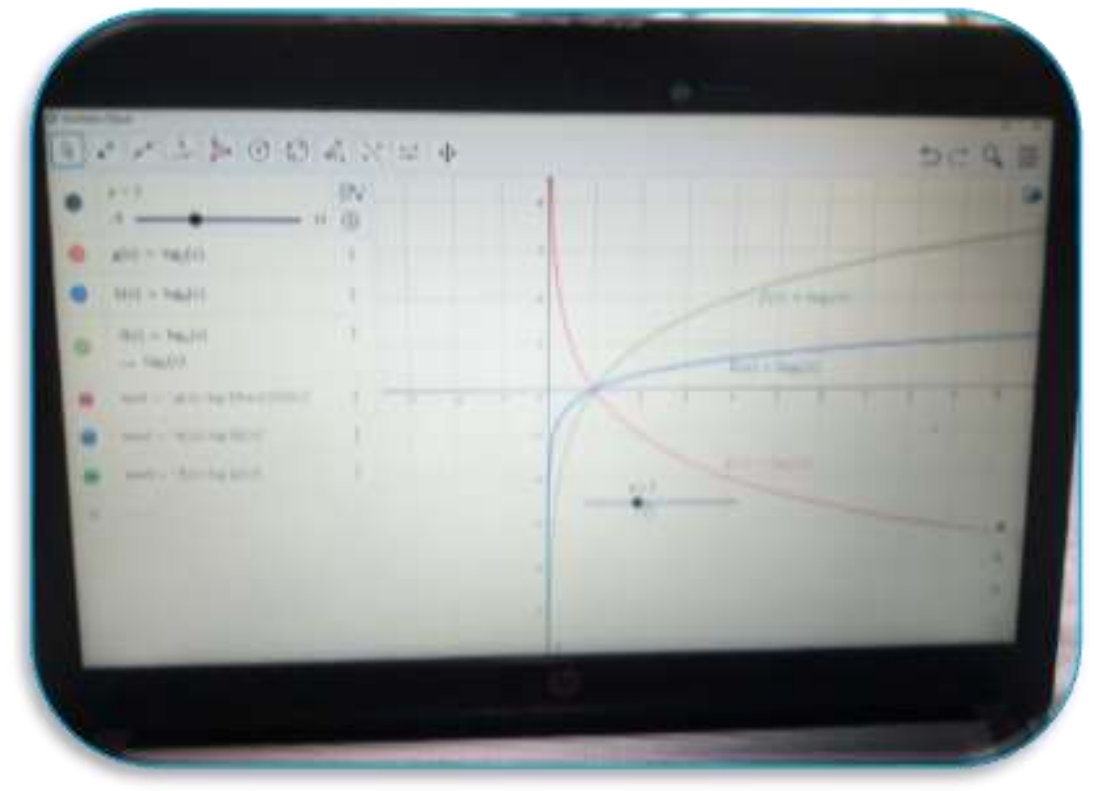

Fig. 2 Students' graphs of $f(x)=\log _{a} x$

The students observed the effects of varying the value of $a$ and found the important properties of these graphs of the form $f(x)=\log _{a} x$ (where $a>0, a \neq 1$, and $x>0$ ). They found that when $a>1$, the function increases for positive $x$, while for $0<a<1$, the function decreased; and they found that for any value of a, the graph always passes through the point $(1,0)$. The graph of $f(x)=\log _{\frac{1}{a}} x$ is a reflection, in the vertical axis of the graph of $f(x)=\log _{a} x$.
Relationship between exponential and logarithmic function While establishing the relationship between exponential and logarithmic functions, the following are the steps followed:

1) Sketch the function $y=e^{x}$

2) Sketch the function $y=x$

3) Reflect the function $y=e^{x}$ on the line $y=x$

4) Find the inverse of $y=e^{x}$ and sketch the function found

5) Observe the effect

The students' activities results are illustrated below.

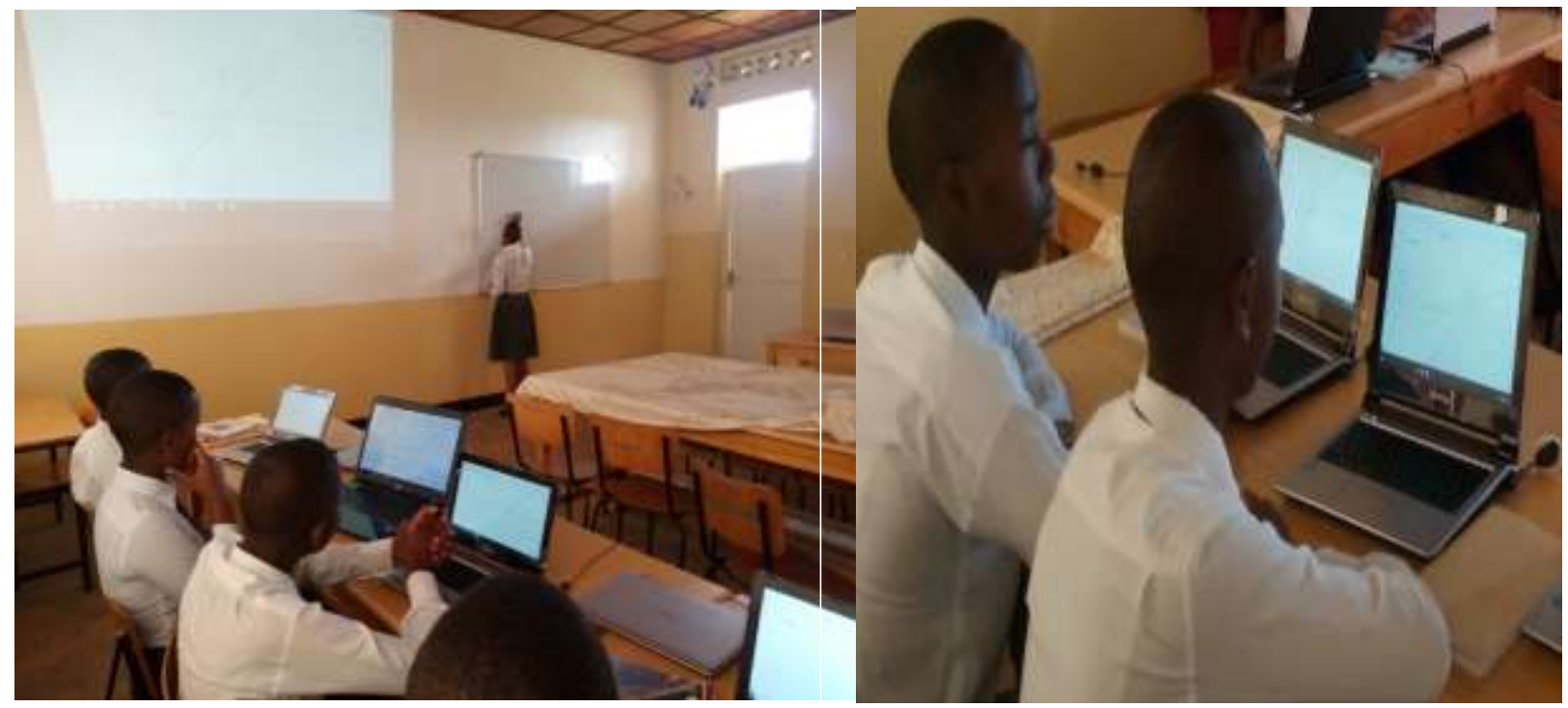

Fig. 3 The relationship between $y=e^{x}$ and $y=\log _{e} x$

While finding the inverse of $y=e^{x}$, students found $y=e^{x}$. After sketching the inverse function, students realized that the exponential function $y=e^{x}$ is a reflection of the logarithmic function $y=\log _{e} x$ to the symmetric line represented by $f(x)=x$. Therefore, students concluded that logarithmic functions are inverses to exponential functions. 
After delivering the lesson, a survey questionnaire was distributed to students to collect information about their satisfaction and attitudes about using GeoGebra software in teaching and learning logarithmic and exponential functions. The responses of students are illustrated in the fig. 4 below.

\section{Students' levels of agreement in \%}

GeoGebra will help me to sketch exponential and other mathematical functions GeoGebra facilitated me to explore and understand the content being taught

$$
\begin{array}{r}
\text { Teaching strategies used were relevant to me } \\
\text { GeoGebra use enhanced my understanding } \\
\text { GeoGebra use made me confident } \\
\text { GeoGebra will help me to perform some Maths activities. } \\
\text { GeoGebra is importantly needed in teaching and learning Maths }
\end{array}
$$

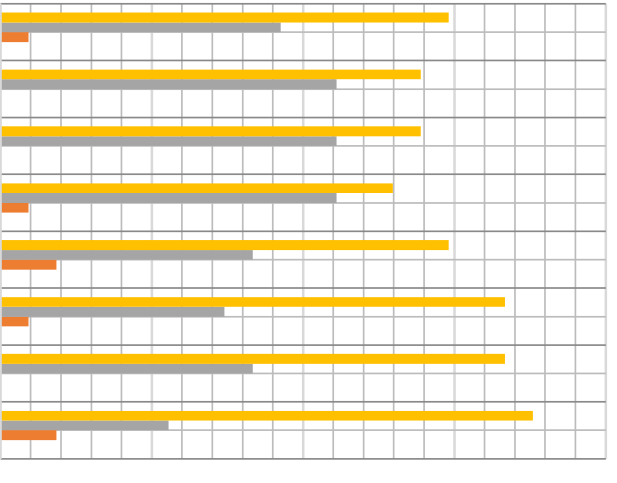

0

20

40

60

80

Strongly Agree $\square$ Agree $\square$ Disagree $\square$ Strongly Disagree

Fig. 4 Students' attitudes about the effectiveness of GeoGebra software in teaching and learning mathematics

From the fig. 4 , the results showed that $70.37 \%$ of the students strongly agreed that the lesson was relevant. In addition, $66.67 \%$ of the students also strongly agreed that GeoGebra is importantly needed in teaching and learning mathematics. With the same percentage, $66.67 \%$ of the students strongly agreed that GeoGebra will help them to perform activities related to that are given by the teacher. When students asked if they feel strongly confident and motivated to explore GeoGebra software, 59.26\% of the students have strongly declared that they feel confident and motivated. With the same percentage of $59.26 \%$, students strongly agreed that GeoGebra will help me to sketch logarithmic and exponential functions easily. While $55.56 \%$ strongly agreed that GeoGebra facilitated them to explore and deeply understand the content being taught.

These results show that students were interested and actively engaged to interact with GeoGebra software to construct their own knowledge. Velichová (2011) also stated that GeoGebra is a dynamic software with pages equipped with vibrant constructions and interactive calculations. Students showed also that they captured the relevance of integrating GeoGebra in teaching and learning Mathematics especially in exploring exponential and logarithmic functions. Indeed, with GeoGebra students can manipulate exponential and logarithmic functions by changing the values of a slider and make different changes in graphic view (Hohenwarter \& Fuchs, 2004). This means that students are enthusiastic, and committed to learn with the use of GeoGebra (Wassie \& Zergaw, 2019). This may be explained by the fact that students got the chance to explore as many graphs as possible in very concrete, clear, precise, and reliable ways, that would not be easy to learn in the conventional classroom environment as was also stresses by Saha et al. (2010). This visualization is a valuable competence and a key of mathematical thinking.

\section{CONCLUSION AND POLICY IMPLICATIONS}

The present study highlighted the effectiveness of GeoGebra in enhancing students' active learning, performance and interest to learn mathematics. The study emphasized on how exponential and exponential functions can be taught effectively with the use of GeoGebra. The study showed that students acquired more knowledge about exponential and logarithmic functions, since they were able to deeply explore the related concepts with the use of dynamic software. Thus, the study results from attitudinal survey questionnaire showed that students' interest has increased.

Though computer distribution is not yet satisfactory in all secondary schools, especially for developing countries, the program of one laptop per student should be emphasized since not all schools are fully equipped with computers. Once students have their own computers, they can interact with the software even when they are at their homes home (Dikovi, 2009; Charles \& Gladys, 2018). There also a need to train teachers about how GeoGebra works since mathematics is still taught in traditional ways.

\section{ACKNOWLEDGMENTS}

The authors acknowledge Dr. Bernard Bahati who designed and monitored this study. The authors also appreciate Dr. Alphonse Uworwabayeho for his valuable comments about this study. 


\section{REFERENCES}

1. Adegoke, I. A. (2016). Geogebra: The Third Millenium Package for Mathematics Instruction in Nigeria. Annals. Computer Science Series, 14(1), $35-43$.

http://analeinformatica.tibiscus.ro/download/lucrari /14-1-05-Akanmu.pdf

2. Arbain, N., \& Shukor, N. A. (2015). The Effects of GeoGebra on Students Achievement. Procedia Social and Behavioral Sciences, 172, 208-214. https://doi.org/10.1016/j.sbspro.2015.01.356

3. Aydos, M. (2015). The Impact of teaching Mathematics with GeoGebra on the conceptual Understanding of Limits and Continuity: the case of Turkish gifted and talented Students [Unpublished Master thesis.Ihsan Dogrammaci Bilkent University]. https://doi.org/10.1377/hlthaff.2013.0625

4. Bester, G., \& Brand, L. (2013). The effect of technology on learner attention and achievement in the classroom. 33(2), 1-15.

5. Biyela, K. B. (2008). The use of computers and Problem solving in Algebra. University of Natal.

6. Boholano, H. (2012). ICT Based Instruction in a Constructivist Classroom. In 4th International Education Conference, 1, 94-98.

7. Botha, J. J. (2011). Between Teachers 'Knowledge and Beliefs and Their. October.

8. Brown, J. S. (2017). SMART SOCIAL NETWORKING : 21 CENTURY TEACHING. 7(1), 21-29. https://doi.org/10.17810/2015.45

9. Choi, K. (2010). Motivating students in learning mathematics with GeoGebra. Annals. Computer Science Series, 8(2).

10. Cohen, L., Manion, L., \& Morrison, K. (2007). Research Methods in Education (6 Edition). Routledge.

11. Dikovi, L. (2009). Applications GeoGebra into Teaching Some Topics of Mathematics at the College Level. Computer Science and Information Systems, 6(2), 191-203. https://doi.org/10.2298/csis0902191D

12. Dockendorff, M., \& Solar, H. (2018). ICT integration in mathematics initial teacher training and its impact on visualization: the case of GeoGebra. International Journal of Mathematical Education in Science and Technology, 49(1), 66-84. https://doi.org/10.1080/0020739X.2017.1341060

13. Ertmer, P. A., \& Ottenbreit-Leftwich, A. T. (2010). Teacher technology change: How knowledge, confidence, beliefs, and culture intersect. Journal of Research on Technology in Education, 42(3), 255284.

https://doi.org/10.1080/15391523.2010.10782551

14. Funkhouser, C. (2003). The effects of computer- augmented geometry instruction on student performance and attitudes. Journal of Research on Computing in Education, 35(2), 163-175.

15. Hohenwarter, M., \& Fuchs, K. (2004). Combination of dynamic geometry, algebra and calculus in the software system GeoGebra.

https://pdfs.semanticscholar.org/137b/7e90b60215 b97afa4fd3fa0edada3ec167b8.pdf

16. Khobo, R. J. (2015). the Effect of Using Computers for the Teaching and Learning of Mathematics To Grade 10 Learners At Secondary School (Doctoral dissertation, University of South Africa).

17. Lombardi, M. M. (2007). Authentic learning for the 21st century: An overview. Educause Learning Initiative, 1(2007), 1-12.

18. Moore, J. W. (2008). Mathematics education. Journal of Chemical Education, 85(8), 1019. https://doi.org/10.4324/9781315146706-38

19. Niess, M. L. (2002). Preparing Teachers to Teach Science and Mathematics with Technology. Networking the Learner, 689-697.

https://doi.org/10.1007/978-0-387-35596-2_69

20. Philip, C., Wozney, L., \& Venkatesh, V. (2006). Implementing Computer Technologies : Teachers ' Perceptions and Practices. Journal of Technology and Teacher Education, 14(1), 173-207.

21. Saha, R. A., Ayub, A. F. M., \& Tarmizi, R. A. (2010). The effects of GeoGebra on mathematics achievement: Enlightening Coordinate Geometry learning. Procedia - Social and Behavioral Sciences, 8, 686-693.

https://doi.org/10.1016/j.sbspro.2010.12.095

22. Shabiralyani, G., Hasan, K. S., Hamad, N., \& Iqbal, N. (2015). Impact of Visual Aids in Enhancing the Learning Process Case Research: District Dera Ghazi Khan. Journal of Education and Practice, 6(19), 226-233.

23. Shadaan, P., \& Eu, L. K. (2013). Effectiveness of Using GeoGebra on Students' Understanding in Learning Circles. The Malaysian Online Journal of Educational Technology, 1(4), 1-11.

24. Vasquez, D. (2015). Enhancing Student Achievement Using Geogebra in a technology rich environment. California State Polytechnic University.

25. Velichová, D. (2011). Interactive maths with GeoGebra. International Journal of Emerging Technologies in Learning, 6(SPECIAL ISSUE.2), 31-35. https://doi.org/10.3991/ijet.v6iS1.1620

26. Wassie, Y. A., \& Zergaw, G. A. (2019). Some of the potential affordances, challenges and limitations of using GeoGebra in mathematics education. Eurasia Journal of Mathematics, Science and Technology Education, 15(8), 1-11. https://doi.org/10.29333/ejmste/108436 
"Effectiveness of GeoGebra towards Students' Active Learning, Performance and Interest to Learn Mathematics"

27. Waxman, H. C., Connell, M. L., \& Gray, J. (2002).

A Quantitative Synthesis of Recent Research on the Effects of Teaching and Learning with Technology on Student Outcomes. North Central Regional Educational Laboratory.

28. Yilmaz, Z., Furkan, H., \& Kutluca, T. (2012). The effect of dynamic mathematics software GeoGebra on student achievement in teaching of trigonometry. Procedia - Social and Behavioral Sciences, 31, 183187.

https://doi.org/10.1016/j.sbspro.2011.12.038 